\title{
A CASA COMO PATRIMÔNIO
}

Hausing as heritage

\section{GERIBELLO, Denise Fernandes}

Centro Universitário de Jaguariúna

RESUMO: Este trabalho explora peculiaridades da habitação como patrimônio cultural. Busca-se apontar alguns dos limites e potencialidades para a compreensão e prática dessa tipologia como patrimônio, ou seja, tecer uma reflexão sobre a complexidade da moradia como patrimônio cultural. $O$ estudo teve como base revisão bibliográfica sobre o tema, bem como eventos científicos.

Palavras-chave: Patrimônio cultural; Habitação; Casas históricas

ABSTRACT: This paper explores the peculiarities of housing as cultural heritage. It aims to discuss some of the limits and potentialities of this typology's comprehension and praxis as heritage. It reflects on the complexity of housing as cultural heritage. The study was based on bibliographic research and scientific events.

Key-words: Cultural heritage; Housing; Historic houses

\section{INTRODUÇÃO}

Dentre os bens que constituem o patrimônio cultural brasileiro, figuram diversas casas: de palacetes de barões e casas-grandes de fazendas a modestas casas de colonos e vilas operárias. Nas últimas décadas, a questão da habitação como patrimônio vem sendo cada vez mais explorada, sob as mais diversas óticas.

Neste artigo, são apresentadas reflexões sobre a habitação como patrimônio cultural, sobretudo sobre casas históricas. O trabalho tem como base revisão bibliográfica sobre o tema, com destaque para artigos em periódicos científicos, bem como seminários e encontros. A reflexão se pauta, ainda, em pesquisas realizadas anteriormente pela autora que, em maior ou menor medida, dialogam como o tema.

Inicialmente, é tecida uma reflexão sobre a arquitetura residencial com relação a diferentes escalas de abordagem. Em seguida, trata-se da tipologia residencial como patrimônio cultural. O texto aborda, então, algumas das peculiaridades das casas histórias. Finalmente, são apontadas as considerações finais.

\section{A CASA E A CIDADE}

A cidade é constituída por uma mescla de cheios e vazios, dos mais variados tamanhos e formas. Uma parcela desses cheios é formada por estruturas faraônicas, muitas delas intencionalmente projetadas com o propósito de imprimir 
determinada identidade a um local. Paços municipais, grandes estádios, obeliscos comemorativos e outras tantas construções de grande porte que se destacam no tecido urbano e que são verdadeiros monumentos. Conforme Choay, "o sentido original do termo [monumento] é o latim monumentum, que por sua vez deriva de monere ("advertir", "lembrar"), aquilo que traz à lembrança alguma coisa" (2001, p.17). Como monumento, as edificações em questão têm poder de evocação. Seu programa, portanto, vai além de seu uso pragmático; elas possuem uma função simbólica, que dá conta de evocar memórias, ideias, identidades.

Apesar do papel de destaque das edificações monumentais no tecido urbano, a feição de grande parte das cidades é dada por outra tipologia: a arquitetura residencial. Os edifícios habitacionais costumam ser a tipologia predominante na paisagem da cidade. Não se pode negar que há entre esses edifícios exemplares concebidos com a função simbólica mencionada acima. Casasmanifesto e residências oficiais podem ser exemplo disto. Todavia, são as habitações despretensiosas, aquelas que não almejam mais do que dar conta das demandas pragmáticas cotidianas, que predominam na paisagem da cidade.

$\mathrm{Na}$ escala da paisagem urbana os edifícios residenciais têm um papel fundamental por constituir a maior parte do construído. A redução da escala de abordagem, todavia, não diminui a relevância dessa tipologia, muito pelo contrário. A habitação é um campo de criação arquitetônica extremamente rico, em suas mais diversas formas. Do vernacular aos sistemas pré-fabricados, a arquitetura residencial apresenta uma miríade de soluções formais, espaciais e tecnológicas. Mas, muito além de um frio sólido que envolve o homem, uma realidade visível e tangível, que pode ser compreendida pela análise de volumes, planos e linhas, a casa, como aponta Coelho, "é vivida pelo homem; adquire valores humanos" (1999, p.9). Nesse sentido, a casa, segundo Bachelard, "é um estado de alma. Mesmo reproduzida no seu aspecto exterior fala de uma intimidade" (1957, p.65). Ao refletir sobre os edifícios habitacionais, portanto, devem ser levadas em conta questões tanto objetivas e quanto subjetivas. Avançando ainda mais, essas questões devem ser tratadas considerando a dimensão temporal. Conforme Lemos,

$O$ ato de morar é uma manifestação de caráter cultural e enquanto as técnicas construtivas e os materiais variam com o progresso, o habitar um espaço, além de manter vínculos com 
a modernidade também está relacionado com os usos e costumes tradicionais da sociedade (1996, p. 8).

A habitação guarda a tensão entre as mudanças e permanências, tanto na dimensão material como nas práticas sociais. Assim, nos informa sobre a sociedade do presente, tanto quanto ilumina a compreensão do passado e das expectativas com relação ao futuro.

\section{A CASA COMO PATRIMÔNIO}

O tema da habitação vem sendo cada vez mais explorado nos estudos sobre patrimônio cultural. Pesquisas, seminários, sessões temáticas em eventos sobre o assunto vêm aumentando em diversas instituições do país. O seminário promovido pelo Centro de Preservação Cultural da USP (CPC) "Habitação como patrimônio cultural", realizado em maio de 2016, é um exemplo dessa tendência. O evento, que teve como desdobramento a publicação de um número especial da Revista $\mathrm{CPC}^{1}$, trouxe reflexões envolvendo abordagens diversas e múltiplos agentes, como poder público, legisladores, pesquisadores, proprietários e mercado imobiliário. Outro evento sobre o tema foi o encontro "Preservação e memória do morar na metrópole", promovido pelo Departamento de História da Arquitetura e Estética do Projeto da Faculdade de Arquitetura e Urbanismo da Universidade de São Paulo, realizado em cinco de maio de 2018. Apenas tomando os trabalhos apresentados nesses dois eventos como amostragem, já é possível identificar uma diversidade significativa de áreas do conhecimento, abordagens e objetos de estudo, que variam quanto ao recorte temporal, espacial e escala.

Apesar de tal diversidade, algumas questões perpassam grande parte das reflexões recentes sobre a habitação como patrimônio. Nota-se que se, por um lado, a habitação constitui um patrimônio muito rico para investigar a arquitetura e a sociedade sob vários aspectos, por outro lado, é uma das tipologias que apresenta maior dificuldade em todas as etapas de preservação, desde o reconhecimento como patrimônio, passando pela documentação, apropriação e conservação, até sua apropriação propriamente dita.

Essa dificuldade decorre, em muitos dos casos, de conflitos resultantes entre os valores patrimoniais e valores de outras ordens atribuídos aos edifícios

\footnotetext{
${ }^{1}$ REVISTA CPC. Número Especial: Habitação como patrimônio cultural. São Paulo, n.22, abr, 2017. Suplemento.
} 
residenciais, sobretudo os valores da habitação. Conforme Turner, os valores da habitação - ou housing values, como utilizado pelo autor - vão muito além das características arquitetônicas e construtivas, como, por exemplo, a solidez da construção, o conforto térmico e acústico. Essa classe de valores pode referir-se à integração do habitante em determinada rede social, à possibilidade de geração de renda nas proximidades, ao sentimento de segurança, às chances de permanência no imóvel, à qualidade de infraestrutura e dos serviços públicos, entre outros (Turner, 1976). Esses critérios não se referem a características estáticas, eles se modificam segundo as dinâmicas urbanas e demandas sociais (GERIBELLO, 2011, p.120). A compreensão de patrimônio cultural como algo estático, que vem sendo muito questionada nas últimas décadas em âmbito acadêmico, mas ainda perdura na prática patrimonial, entra em choque com a plasticidade da arquitetura residencial. Nesse sentido, a busca de caminhos para equacionar a permanência da edificação e de seu significado patrimonial com as modificações necessárias para atender as demandas de seus moradores constitui uma linha de pesquisa fundamental.

Nem todo o patrimônio habitacional, entretanto, é composto por habitações que mantém seu uso inicial. Quanto trata-se de casas históricas, predominam as edificações que tiveram seu uso convertido em museus e centros culturais.

\section{CASAS HISTÓRICAS}

Entende-se por "casa histórica" as casas relacionadas a alguma figura pública de relevância ou a algum acontecimento histórico de um determinado local (Ponte, 2007, p. 3). Trata-se de um grupo pouco expressivo dentro do rol de exemplares tutelados pelo Iphan. Conforme listagem realizada por Ribeiro, entre os mais de mil bens preservados pelo órgão, há apenas 33 casas históricas inscritas apenas no Livro do Tombo Histórico, 12 inscritas tanto no Livro do Tombo Histórico quanto no de Belas Artes e 10 apenas no Livro de Belas Artes (2012, p. 226-230). O autor aponta que, por parte do Iphan,

Nunca houve, de fato, um interesse maior em acautelar esse tipo de edificação. A maior parte dos tombamentos nessa rubrica derivou ou de um interesse artístico que o imóvel apresentasse ou, de outro lado, da solicitação de membros da sociedade. E a Casa atendia (Ribeiro, 2012, p.233). 
Por um lado, a falta de interesse na tutela desses bens decorre do privilégio conferido ao valor artístico em detrimento do histórico, evidente nas primeiras décadas de existência do Iphan. Além disso, se relaciona à valorização do caráter processualístico da história, que marca a atuação do órgão desde suas primeiras ações sob direção de Rodrigo Melo Franco de Andrade e que se fortalece ao incorporar novas questões metodológicas da história. Essa perspectiva se distanciava da abordagem factual e biográfica que era então associada às casas históricas.

Apesar de fugir do escopo de atuação do Iphan, a valorização de casas históricas estava presente na proposta de sua criação. Ao tratar das obras referentes à "arte histórica", o Capítulo II do anteprojeto do Serviço do Patrimônio Artístico Nacional, escrito por Mário de Andrade em 1936, insere na categoria "monumentos" obras que não são dignas de admiração sob o ponto de vista de arte pura, mas que devem ser conservadas, dentre outros fatores, "porque viveram nelas figuras ilustres da nacionalidade - a casa de Tiradentes em São João Del Rei, a casa de Rui Barbosa" (Sphan/pró-Memória, 1980, p.58).

Uma terceira perspectiva com relação ao assunto é apresentada em um artigo publicado pelo técnico do Iphan Marcus Tadeu Daniel Ribeiro na edição de número 34 da Revista do Patrimônio Histórico e Artístico Nacional, publicação do Iphan que é um dos principais locus de discussão sobre o patrimônio cultural no Brasil. Após realizar um balanço sobre a preservação de casas históricas ao longo da trajetória do Iphan, Ribeiro enfatiza a relevância da tutela desses edifícios, porém sua justificativa vai muito além da celebração de individualidades, como sugeria Andrade. Para ele,

Quando se preserva uma casa histórica não se cultua a imagem de um personagem tanto quanto se busca compreender, pela ação de um intelectual, cientista, artista, militar ou qualquer outro profissional, toda a mentalidade de uma época e aspectos reveladores de que necessita a história cultural como matéria prima (Ribeiro, 2012, p.244).

Nesse sentido, a tutela de casas históricas tem como objetivo documentar a história de maneira mais aprofundada e crítica. Na mesma perspectiva, Siqueira coloca que essas casas devem ser compreendidas como objetos de conhecimento e fruição e sua preservação deve permitir qualificar a vida dos cidadãos por meio do 
entendimento do passado (2016, p. 192). A proposta de Siqueira, todavia, destoa do cenário com o qual ela se depara ao pesquisar a preservação das casas do Conselheiro Rodrigues Alves (Guaratinguetá, SP) e do Barão de Jundiaí (Jundiaí, $\mathrm{SP}$ ), em que a valorização se restringe à agência individual das personalidades. $\mathrm{O}$ aprofundamento da compreensão das casas históricas depende do deslocamento da valorização de uma personalidade, de maneira desvinculada da materialidade da edificação, para uma reflexão sobre a dimensão de habitação presente na casa, abrindo portas para compreensão de aspectos históricos, arquitetônicos, sociais, antropológicos, entre outros, que caracterizam os modos de vida específicos.

É fundamental que as casas históricas sejam consideradas tendo em vista tanto a complexidade quanto as potencialidades do patrimônio residencial, ou seja, mais que pensar a relevância da casa histórica a partir do papel fortuito de personagens e acontecimentos, deve-se buscar pensa-la como espaço habitado, que representa as especificidades de nossa sociedade de forma mais ampla.

Além de refletir sobre a mudança de abordagem com relação às casas históricas, avançando nos caminhos apontados por Ribeiro e Siqueira, é necessário explorar um possível alargamento dos exemplares preservados. Adotando como recorte as casas históricas tuteladas pelo IPHAN, uma análise preliminar, realizada a partir da "Lista de bens tombados e processos de tombamento em andamento", demonstra que, em sua maior parte, as edificações tombadas estão associadas a figuras ou acontecimentos enquadrados em uma perspectiva elitista, masculina e branca da história do país. Dentre esses bens estão a Casa de Rui Barbosa, Marechal Deodoro e Benjamin Constant. Também há casas históricas relacionadas a intelectuais, literatos e cientistas, como Santos Dumont, Euclides da Cunha e Oswaldo Cruz, que muitas vezes não fazem parte das elites econômicas, mas que são figuras chanceladas por elas. Raros são os exemplares de casas históricas relacionadas a mulheres, como é o caso da Casa de Ana Nery. As Casas da Marquesa de Santos e da Chica da Silva também são tuteladas, mas não estão inscritas no Livro do Tombo Histórico, apenas no de Belas Artes. Da mesma forma, os negros, indígenas e as classes populares praticamente não são representados

\footnotetext{
${ }^{2}$ Análise realizada a partir da "Lista de bens tombados e processos de tombamento em andamento", atualizada em nove de dezembro de 2015. Disponível em: http://portal.iphan.gov.br/uploads/ckfinder/arquivos/Lista\%20Bens\%20Tombados\%20Dez\%202015.pd f, acesso em 18 ago 2017.
} 
nesse rol. Pode-se dizer, então, que as casas históricas tuteladas pelo IPHAN não dão conta de representar os diferentes grupos formadores da sociedade brasileira, como aponta a Constituição de 1988.

\section{CONSIDERAÇÕES FINAIS}

Esta breve reflexão buscou levantar questões com relação à preservação de edificações residenciais, identificando algumas das potencialidades dessa tipologia para a compreensão de nossa arquitetura, cultura e sociedade. Da mesma forma, foram apontadas questões desafiadoras para o reconhecimento e preservação desses bens como patrimônio cultural, que conformam possíveis caminhos de investigação a serem seguidos.

\section{REFERÊNCIAS BIBLIOGRÁFICAS}

BACHELARD, Gaston. A poética do espaço. Rio de Janeiro: Livraria Eldorado Tijuca, 1957.

CAMARGO, Mônica J. Apresentação: A habitação na aproximação entre universidade, poder público e sociedade. Revista CPC, São Paulo, n. 22, p. 05-10, 2017. Disponível em: < https://www.revistas.usp.br/cpc/article/view/130994>. Acesso em 29 jun 2018.

CHOAY, Françoise. A alegoria do patrimônio. São Paulo: Estação Liberdade/Ed.UNESP, 2001.

COELHO, Olinio. Prefácio. In: VERÍSSIMO, Francisco; BITTAR, Willian. 500 Anos da Casa no Brasil: as transformações da arquitetura e da utilização do espaço de moradia. Rio de Janeiro: Ediouro, 1999.

GERIBELLO. Denise F. Habitar o patrimônio cultural: o caso do ramal ferroviário Anhumas Jaguariúna. Dissertação (Mestrado em História). Instituto de Filosofia e Ciências Humanas da Universidade Estadual de Campinas. Campinas, 2011.

LEMOS, Carlos A. C.. A Casa Brasileira. São Paulo: Contexto, 1996.

PONTE, António. Casas-Museu em Portugal: Teoria e Prática, 2007. Dissertação (Mestrado). Universidade de Letras do Porto, Porto.

RIBEIRO, Marcus T. D. Entre o ser e o coletivo o tombamento das casas históricas. Revista do Patrimônio Histórico e Artístico Nacional, n.34, 2012.

SIQUEIRA, Lucília S. O conhecimento sobre o passado dos bens tombados que abrigam museus: o Solar do Barão de Jundiaí e a Casa de Prudente de Moraes. Estud. hist. Rio de Janeiro, v. 29, n. 57, p. 169-194, Apr. 2016. Disponível em <http://www.scielo.br/pdf/eh/v29n57/0103-2186-eh-29-57-0169.pdf>, acesso em 6 jun 2018. 
A história que foi usada nos tombamentos e na conservação da Casa do Conselheiro Rodrigues Alves. Revista CPC, São Paulo, n. 19, p. 49-79, jun 2015. Disponível em <https://www.revistas.usp.br/cpc/article/view/90781/97625>, acesso em 6 jun 2018.

SPHAN/Fundação Nacional pró-Memória. Proteção e revitalização do patrimônio

histórico e artístico nacional: uma trajetória. Brasilia: MinC/Sphan/Pró-Memória, 1980. Disponível em <http://portal.iphan.gov.br/uploads/ckfinder/arquivos/

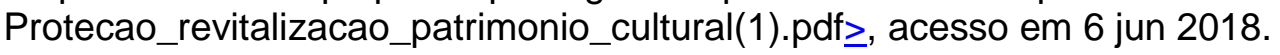

Turner, John F. Housing By People. London: Marion Boyars, 1976. 